\title{
Therapeutic Administration of $\mathrm{KM}^{+}$Lectin Protects Mice Against Paracoccidioides brasiliensis Infection via Interleukin-12 Production in a Toll-Like Receptor 2-Dependent Mechanism
}

Kely C. Coltri, ${ }^{*}$ Leandro L. Oliveira, ${ }^{\star}$ Camila F. Pinzan, ${ }^{*}$ Patrícia E. Vendruscolo, ${ }^{*}$ Roberto Martinez, ${ }^{\dagger}$ Maria Helena Goldman, ${ }^{\ddagger}$ Ademilson Panunto-Castelo, $\$$ and Maria-Cristina Roque-Barreira*

From the Departamento de Biologia Celular e Molecular e Bioagentes Patogênicos, ${ }^{*}$ Faculdade de Medicina de Ribeirão Preto, Departamento de Clínica Médica, ${ }^{\dagger}$ Faculdade de Medicina de Ribeirão Preto, Departamento de Biologia, ${ }^{\ddagger}$ Faculdade de Filosofia, Ciências e Letras de Ribeirão Preto, and Departamento de Enfermagem Geral e Especializada, ${ }^{5}$ Escola de Enfermagem de Ribeirão Preto, Universidade de São Paulo, São Paulo, Brazil

$\mathrm{KM}^{+}$is a mannose-binding lectin from Artocarpus integrifolia that induces interleukin (IL)-12 production by macrophages and protective $T$ helper $1 \mathrm{im}$ mune response against Leishmania major infection. In this study, we performed experiments to evaluate the therapeutic activity of jackfruit $\mathrm{KM}^{+}\left(\mathrm{jfKM}^{+}\right)$and its recombinant counterpart $\left(\mathrm{rKM}^{+}\right)$in experimental paracoccidioidomycosis. To this end, $\mathrm{jfKM}^{+}$or $\mathbf{r K M}^{+}$ was administered to $\mathrm{BALB} / \mathrm{c}$ mice 10 days after infection with Paracoccidiodes brasiliensis. Thirty days postinfection, lungs from the $\mathrm{KM}^{+}$-treated mice contained significantly fewer colony-forming units and little to no organized granulomas compared to the controls. In addition, lung homogenates from the $\mathrm{KM}^{+}$-treated mice presented higher levels of nitric oxide, IL-12, interferon- $\gamma$, and tumor necrosis factor- $\alpha$, whereas higher levels of IL- 4 and IL-10 were detected in the control group. With mice deficient in IL-12, Toll-like receptor (TLR) 2, TLR4, or TLR adaptor molecule MyD88, we demonstrated that $\mathrm{KM}^{+}$led to protection against $P$. brasiliensis infection through IL-12 production, which was dependent on TLR2. These results demonstrated a beneficial effect of $\mathbf{K M}^{+}$ on the severity of $P$. brasiliensis infection and may expand its potential use as a novel immunotherapeu- tic molecule. (Am J Pathol 2008, 173:423-432; DOI: 10.2353/ajpath.2008.080126)

Paracoccidioides brasiliensis is a thermally dimorphic fungus that causes paracoccidioidomycosis (PCM), the most prevalent human systemic mycosis in Latin America, and which is endemic in Brazil, Argentina, Venezuela, and Colombia. This infection is acquired by inhalation of airborne propagules found in nature, which reach the lungs and are converted to the yeast form. ${ }^{1,2}$ The yeasts can be either eliminated by immune competent cells or spread into tissues through lymphatic or hematogenous routes. As a consequence, the disease may develop into multiple forms, ranging from asymptomatic pulmonary infection to severe and disseminated forms. ${ }^{3,4}$ It has been reported that a high level of humoral immune response is associated with increased disease dissemination. ${ }^{5}$ Conversely, the cell-mediated immune response represents the main mechanism of defense in PCM. ${ }^{1}$ Resistance to this mycosis results from the commitment of $\mathrm{CD}^{+} \mathrm{T}$ helper (Th) precursors to the Th1 lineage, ${ }^{6,7}$ stimulated by early secretion of interleukin (IL)-12, ${ }^{8-10}$ and followed by sustained secretion of interferon (IFN)- $\gamma .{ }^{11}$

$\mathrm{IL}-12$ is primarily produced in response to the interaction of Toll-like receptors (TLR) on phagocytes and dendritic cells with pathogen-associated molecular patterns. More often, the TLR signaling involves the adaptor molecule myeloid differentiation primary response gene 88

Supported by grants from Fundação de Amparo à Pesquisa do Estado de São Paulo (FAPESP) (00/09333-2), Conselho Nacional de Desenvolvimento Cientifico e Tecnológico (350418/00-4), and Coordenacão de Aperfeiçoamento de Pessoal de Nivel Superior. K.C.C. received a Ph.D. research fellowship from FAPESP (02/12725-5 and 06/60642-2).

Accepted for publication May 13, 2008

Address reprint requests to Maria-Cristina Roque-Barreira, Departamento de Biologia Celular e Molecular e Bioagentes Patogênicos, Faculdade de Medicina de Ribeirão Preto, Universidade de São Paulo, Av. Bandeirantes, 3900, Prédio Central, 14049-900-Ribeirão Preto, São Paulo, Brazil. E-mail: mcrbarre@fmrp.usp.br. 
(MyD88) and induces nuclear factor- $\kappa \mathrm{B}-$ dependent cytokine production. Only TLR3 and TLR4 use a MyD88independent signaling pathway and engage the adaptor molecule Toll/IL-1R (TIR)-domain-containing adaptor protein inducing IFN- $\beta$ (TRIF; also known as TICAM1). Secreted IL-12 acts on T lymphocytes by inducing cell proliferation and differentiation, as well as production of type 1 cytokines. This sequence of events initiates and amplifies the innate and adaptive Th1-mediated immunity.

Lipopolysaccharides, peptidoglycans, and foreign nucleic acids derived from microbes are the main ligands for TLRs. ${ }^{12}$ Only a few proteins are known to be TLR ligands, ${ }^{12,13}$ and rarely are TLRs reported to be endowed with the capacity of recognizing sugars. ${ }^{14}$ Some studies have shown the involvement of lectins in cell signaling initiated by TLRs, ${ }^{14-16}$ as well as in the induction or amplification of IL-12 ${ }^{17,18}$ and IFN- $\gamma^{19,20}$ production.

Our group has previously shown that BALB/c mice prophylactically treated with $\mathrm{KM}^{+}$, a D-mannose-binding lectin from the seeds of Artocarpus integrifolia, develop a Th1 protective response against Leishmania major infection. ${ }^{21}$ Since resistance to $P$. brasiliensis infection also correlates with an efficient Th1 immune response, we determined whether treatment with jfKM ${ }^{+}$(isolated from jackfruit seeds) as well as its recombinant counterpart $\left(\mathrm{rKM}^{+}\right)$could modify the course of experimental PCM. We demonstrate that the therapeutic administration of either jfKM ${ }^{+}$or $\mathrm{rKM}^{+}$ protects against experimental PCM. By using genetically deficient strains of mice, we show that IL-12 plays a key role in the protective effect induced by $\mathrm{KM}^{+}$by a mechanism dependent on TLR2/MyD88 signaling.

\section{Materials and Methods}

\section{Mice}

In this study, we used 6- to 8-week-old male mice of the following strains: BALB/c, C57BL/6 (WT for the deficient mice), IL-12 $2^{-1-}$, NOS2 ${ }^{-1-}$ (nitric oxide synthase 2 defi-

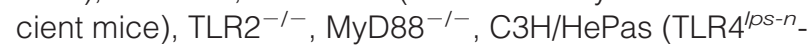
expressing a functional TLR4), and $\mathrm{C} 3 \mathrm{H} / \mathrm{HeJ}$ (TLR4 ${ }^{\text {Iss-d }}$ expressing a nonfunctional TLR4). The mice were bred and maintained under standard conditions in the animal house of the Medical School of Ribeirão Preto, University of São Paulo, Ribeirão Preto, São Paulo, Brazil. Genedeficient mice were obtained from the Jackson Laboratories (Bar Harbor, ME). All experiments were performed in accordance with the guidelines of the Animal Care Committee of the university.

\section{Fungal Isolate}

The virulent $P$. brasiliensis isolate (Pb18) used in this study was cultured in Fava-Netto's semisolid medium at $36^{\circ} \mathrm{C}$ for 7 days as described elsewhere. ${ }^{22}$ To maintain virulence, two consecutive passages in mice were accomplished by intravenous infection, and the yeasts recovered from the lung tissue were reisolated in culture medium, as described above. The viability of the yeast cells, determined by fluorescein diacetate and ethidium bromide staining, ${ }^{23}$ was always greater than $90 \%$.

\section{$\mathrm{KM}^{+}$Affinity Purification}

$\mathrm{KM}^{+}$, a mannose-binding lectin extracted from jackfruit seeds (Artocarpus heterophyllus Lam. Syn. A. integrifolia L.f.), was purified as previously described. ${ }^{24} \mathrm{rKM}^{+}$was expressed in Escherichia coli BL21 transformed with pExp- $\mathrm{KM}^{+}$, as detailed previously. ${ }^{25}$ To extract soluble proteins, the bacterial suspensions were sonicated and spun at $25,000 \times g$ for 15 minutes. The supernatants containing soluble proteins were affinity-purified on a D-mannose column, as in the case of $\mathrm{fKKM}^{+}$isolation. $\mathrm{KM}^{+}$preparations (from plant or recombinant) contained less than $0.05 \mathrm{ng} / \mathrm{ml}$ of bacterial endotoxin, as determined by the Limulus amoebocyte lysate assay (Sigma Chemical Co., St. Louis, MO).

\section{$\mathrm{KM}^{+}$Administration and Intravenous Infection of Mice}

$\mathrm{BALB} / \mathrm{C}, \mathrm{C} 57 \mathrm{BL} / 6, \mathrm{IL}-12^{-1-}$, or NOS2 ${ }^{-1-}$ mice (three mice per group) were infected by intravenous injection into the lateral tail vein with $0.1 \mathrm{ml}$ of the inoculum $(1 \times$ $10^{6} \mathrm{P}$. brasiliensis yeast cells). The uninfected control mice were inoculated with $0.1 \mathrm{ml}$ of sterile pyrogen-free phosphate-buffered saline (PBS). To determine the most effective regimen of $\mathrm{KM}^{+}$administration, seven groups of infected BALB/c mice were injected with $0.5 \mu \mathrm{g}$ of $\mathrm{KM}^{+}$in $50 \mu \mathrm{l}$ of PBS after intravenous $P$. brasiliensis challenge. These treatments varied according to the number of $\mathrm{KM}^{+}$ injections (one to three doses), administration route (intraperitoneal or subcutaneous), and time intervals between the $\mathrm{KM}^{+}$injection and the challenge with $P$. brasiliensis. On the basis of the results provided by these screening procedures, we used the protocol in which the infected mice were injected with a single subcutaneous dose of $\mathrm{KM}^{+}$on day 10 postinfection in the subsequent experiments. The control groups, which received a similar regimen, were injected with PBS $(50 \mu \mathrm{l})$ instead of $\mathrm{KM}^{+}$. The course of infection was evaluated on days 14 and 30 postinfection.

\section{Spleen Cell Cultures}

Suspensions of spleen cells from the C57BL/6, TLR2 ${ }^{-1-}$, ${\mathrm{MyD} 88^{-1-}}, \mathrm{C} 3 \mathrm{H} / \mathrm{HePas}$, and $\mathrm{C} 3 \mathrm{H} / \mathrm{HeJ}$ mice were washed in RPMI-I (RPMI 1640, Flow Laboratories, Inc., McLean, VA) and treated with lysing buffer ( 9 parts 0.16 $\mathrm{mol} / \mathrm{L}$ ammonium chloride and 1 part $0.17 \mathrm{~mol} / \mathrm{L}$ Tris- $\mathrm{HCl}$, $\mathrm{pH}$ 7.5) for 4 minutes. The erythrocyte-free cells were washed three times in RPMI-I, resuspended in RPMI-C containing $2 \mathrm{mmol} / \mathrm{L}$ L-glutamine, $50 \mu \mathrm{mol} / \mathrm{L}$ 2-mercaptoethanol, $100 \mathrm{U} / \mathrm{ml}$ penicillin, $100 \mu \mathrm{g} / \mathrm{ml}$ streptomycin (Sigma-Aldrich), and $5 \%$ heat-inactivated fetal calf serum (Hyclone, Logan, UT), and dispensed into 24-well cell culture plates $\left(1 \times 10^{7}\right.$ cells/well). After 2 to 4 hours of incubation at $37^{\circ} \mathrm{C}$, the nonadherent cells were removed 
by exhaustive washing with RPMI-I, and the adherent cells were incubated with $\mathrm{KM}^{+}(5 \mu \mathrm{g} / \mathrm{ml})$, zymosan (10 $\mu \mathrm{g} / \mathrm{ml}$ ), which had been previously boiled for 30 minutes and washed twice with PBS or lipopolysaccharide (10 $\mu \mathrm{g} / \mathrm{ml}$ ) in RPMI-C. Some cultures were also incubated with $50 \mathrm{mmo} / \mathrm{L}$ D-mannose. After 48 hours of incubation, the supernatants were harvested by centrifugation and stored at $-20^{\circ} \mathrm{C}$ until enzyme-linked immunosorbent assay (ELISA)-based cytokine measurements were performed.

\section{CFU Assay}

The mice were euthanized 14 and 30 days postinfection and examined for fungal burdens in the lungs, as previously described. ${ }^{26}$ Briefly, one lung of each animal was aseptically removed and disrupted in $1 \mathrm{ml}$ of PBS containing $1.6 \mathrm{mmol} / \mathrm{L}$ phenylmethylsulfonyl fluoride (Sigma Chemical Co.), using a tissue homogenizer (Ultra-Turrax T25 Basic, IKA Works, Inc., Wilmington, NC). The number of viable $P$. brasiliensis organisms was determined by plating crude and serially diluted homogenates onto brain heart infusion agar, BHI (Oxoid Ltd., Hampshire, UK) supplemented with $4 \%(\mathrm{v} / \mathrm{v})$ of heat-inactivated fetal calf serum (Gibco BRL, Gaithersburg, MD) and incubated at $36^{\circ} \mathrm{C}$ for 15 days. The lower limit of detection was $10 \mathrm{CFU}$. The number of $P$. brasiliensis colonies per gram of organ was given as the mean and SD. The lung homogenate supernatants were also separated from cell debris by centrifugation at $2000 \times g$ for 15 minutes and stored at $-20^{\circ} \mathrm{C}$ until ELISA-based cytokine and nitric oxide (NO) measurements were performed.

\section{ELISA-Based Cytokine Detection Assay}

The levels of IL-12p70, IL-4, IL-10, IFN- $\gamma$, and tumor necrosis factor (TNF)- $\alpha$ in the supernatants of the lung homogenate were measured by capture ELISA with antibody pairs purchased from PharMingen (San Diego, CA). The ELISA procedure was performed according to the manufacturer's protocol. The cytokine concentrations were determined with reference to a standard curve for serial twofold dilutions of the murine recombinant cytokines. Additionally, macrophage supernatants from the C57BL/6 (WT), $\mathrm{TLR}^{-/-}$, TLR4 $4^{-/-}$and MyD88 ${ }^{-1-}$ mice were harvested for IL-12p70 detection.

\section{NO Production}

NO production was quantified by the standard Griess reaction. Briefly, $50 \mu \mathrm{l}$ of supernatants from the lung homogenates were incubated with an equal volume of Griess reagent ( $1 \%$ sulfanilamide, $0.1 \%$ naphthylene diamine dihydrochloride, and $2.5 \% \mathrm{H}_{3} \mathrm{PO}_{4}$ ) at room temperature, for 10 minutes. The absorbance was measured at $550 \mathrm{~nm}$ in a microplate scanning spectrophotometer (Power Wave X, Bio-Tek Instruments, Inc., Winooski, VT). The conversion of absorbance into micromolar concentrations of $\mathrm{NO}$ was deduced from a standard curve using a known concentration of $\mathrm{NaNO}_{2}$.

\section{Analysis of Cell Populations in the BALF}

To assess different cell types present in the lungs of the $\mathrm{KM}^{+}$-treated or non-treated mice, the bronchoalveolar lavage fluid (BALF) was analyzed. For cell isolation, lungs were rinsed 5 times with $1 \mathrm{ml}$ of PBS, and $1 \times 10^{4}$ cells per cytocentrifuge chamber (Shandon, Sewickley, PA) were spun onto slides and stained with modified WrightGiemsa stain (Hema 3 stain set; Fisher Scientific, Pittsburgh, PA). To assess cell populations, approximately 100 to 200 cells were counted from each slide and classified according their morphological characteristics.

Pulmonary lymphocyte populations were analyzed by flow cytometry. Cells were prepared as described above and stained for $\mathrm{CD} 19^{+}, \mathrm{CD}^{+}$, or $\mathrm{CD} 8^{+}$surface markers by incubation for 30 minutes on ice with fluorescein isothiocyanate- or phycoerythrin-conjugated specific antibodies. Cells were washed three times in PBS/2\% fetal calf serum, fixed in $0.5-2 \%$ buffered paraformaldehyde, and analyzed using a FACScan flow cytometer (Becton Dickinson, San Jose, CA).

\section{Histopathological Analysis}

On day 30 postinfection, one lung of each mouse was removed, fixed in 10\% phosphate-buffered formalin for 24 hours, and embedded in paraffin. Five-micrometer sections were stained with hematoxylin and eosin, and the granulomatous lesions were analyzed by light microscopy.

\section{Statistical Analysis}

Statistical determinations of the difference between means of experimental groups were performed using one-way analysis of variance (analysis of variance) followed by Bonferroni post-test. Differences that provided $P<0.05$ were considered to be statistically significant. All experiments were performed at least three times.

\section{Results}

Treatment of P. brasiliensis-Infected Mice with $K M^{+}$Decreases Fungal Burden and Lung Injury

To evaluate whether $\mathrm{KM}^{+}$is able to ameliorate PCM in the murine model and to determine the most effective regimens of $\mathrm{KM}^{+}$administration, groups of BALB/c mice were subjected to several treatments that varied according to the number, route, and injection time intervals. CFU recovery from the lungs, a key parameter to evaluate the course of experimental PCM, showed that all regimens of $\mathrm{KM}^{+}$administration resulted in significant reduction of the fungal burden. Since the lowest CFU number was associated with the administration of a single subcutaneous dose of $\mathrm{KM}^{+}$on day 10 postinfection, this protocol was used in all of the subsequent experiments.

The progression of $P$. brasiliensis infection in the BALB/c mice injected with jfKM ${ }^{+}, \mathrm{rKM}^{+}$, or vehicle (PBS) after intravenous infection was compared in terms of 
A
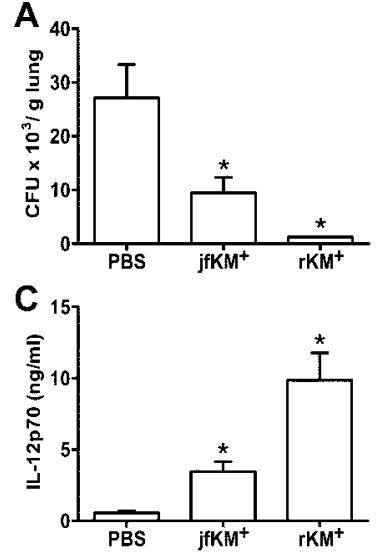

E

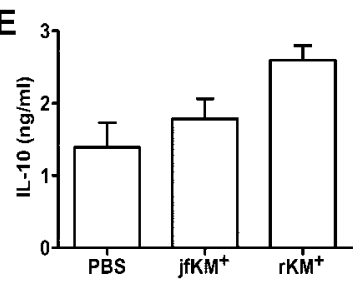

B
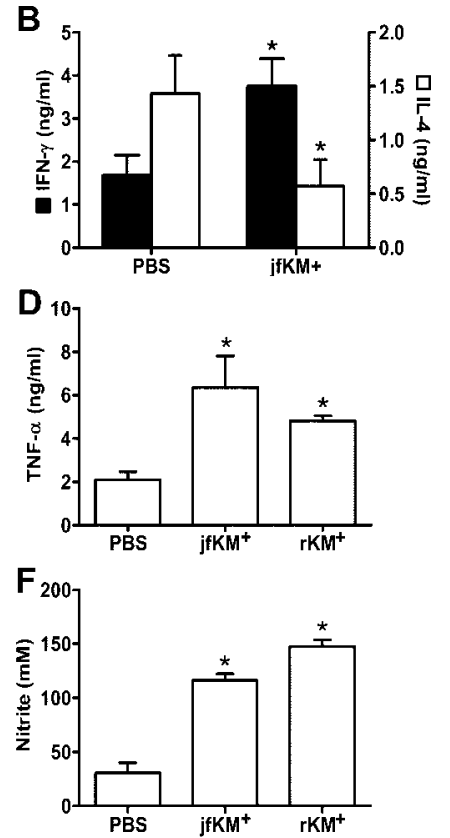

Figure 1. Therapeutic effect of $\mathrm{KM}^{+}$on $P$. brasiliensis infection. Mice inoculated with $10^{6}$ yeast cells were treated with $\mathrm{fKM}^{+}, \mathrm{rKM}^{+}$, or PBS (as a control). The lung homogenates obtained from these mice were analyzed at 30 days postinfection. A: CFU. B-E: Cytokine levels. F: Nitrite concentrations. Assays were performed in triplicate and the results represent the mean \pm SD of at least three independent experiments. ${ }^{*} P<0.05$ versus control group.

fungal burden. The number of CFU recovered from the lungs of mice treated with both $\mathrm{jfKM}^{+}$and $\mathrm{rKM}^{+}$at 30 days postinfection was approximately 65\% and 95\% lower than the number recovered from the nontreated control mice (PBS), respectively (Figure $1 \mathrm{~A}$ ). $\mathrm{KM}^{+}$administration prevented fungal permanence in infected mice, since no CFU burden was detected in the liver or spleen on days 30 and 60 postinfection, whereas control mice still presented in the liver $5.3 \times 10^{3}$ and $1.2 \times 10^{3}$ yeasts $/ g$ and in the spleen $1 \times 10^{3}$ and $0.4 \times 10^{3}$ yeasts/g on days 30 and 60 postinfection, respectively.

The pulmonary histopathology was also compared. On day 30 after intravenous infection, the lungs from nontreated mice (PBS) presented multiple sites of focal and confluent epithelioid granulomas with lymphomonocytic halos circumscribing a high number of viable and nonviable yeast cells (Figure 2, A and $\mathrm{C}$ ). In addition, on days 30 and 60 after $P$. brasiliensis infection, multiple and confluent typical epithelioid granulomas were observed in the liver and spleen from this control group (data not shown). In contrast, in the $P$. brasiliensis-infected mice therapeutically injected with jfKM ${ }^{+}$or $\mathrm{rKM}^{+}$, no granulomas or yeast cells were seen in the pulmonary sections, and the bronchoalveolar architecture was well preserved (Figure 2, B and D). There were no granulomas in the liver or spleen at any of the assessed times (data not shown).

Since the leukocytes contained in the bronchoalveolar fluid reflects the lung content of inflammatory cells, ${ }^{27}$ we examined the cell populations in the BALF from infected mice treated with $\mathrm{KM}^{+}$or not. BALF from infected mice treated with vehicle presented larger numbers of cells compared to $\mathrm{KM}^{+}$-treated mice (Figure 3A). This differ-
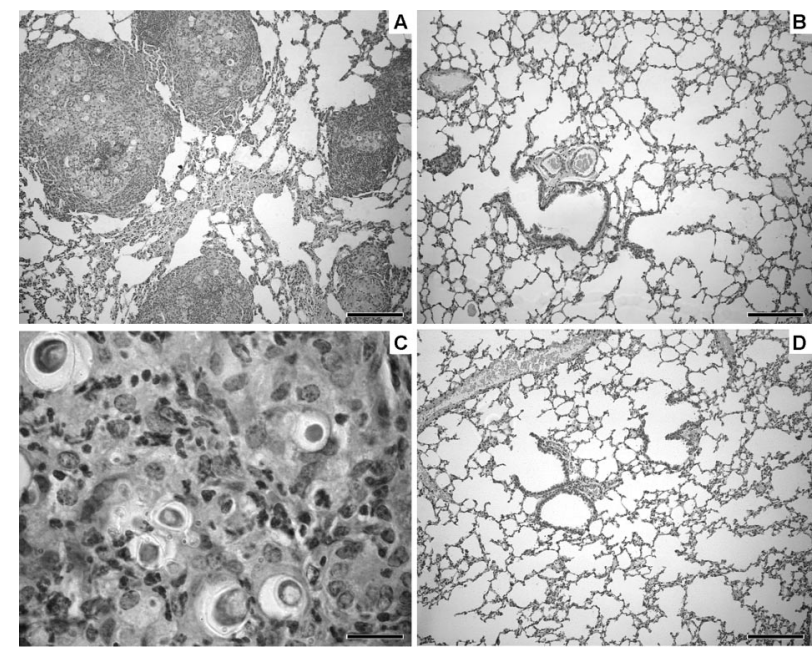

Figure 2. Therapy with $\mathrm{KM}^{+}$leads to resolution of the pulmonary lesions in $P$. brasiliensis-infected mice. Lung histopathology of $P$. brasiliensis-infected mice treated therapeutically with $\mathrm{ffKM}^{+}$(B) or $\mathrm{rKM}^{+}$(D). PBS was administered to control animals ( $\mathbf{A}$ and $\mathbf{C}$ ). The lung sections obtained on day 30 postinfection were H\&E stained. The mice injected with PBS (A and $\mathbf{C}$ ) presented extensive and confluent lesions, with epithelioid granulomas surrounding a large number of viable and nonviable yeast cells. The mice treated with j $\mathrm{fKM}^{+}$(B) or $\mathrm{rKM}^{+}$(D) presented no granulomas or yeast cells. Scale bars: $\mathbf{A}, \mathbf{B}, \mathbf{D}=200 \mu \mathrm{m} ; \mathbf{C}=20 \mu \mathrm{m}$.

ence was related to neutrophils and lymphocytes, since the number of these cells in vehicle-treated mice was seven- and twofold higher than those treated with $\mathrm{KM}^{+}$, respectively $(P<0.05)$. There was no significant difference in the number of macrophages between vehicle and $\mathrm{KM}^{+}$-treated mice (Figure $3 \mathrm{~A}$ ). Analysis of BALF

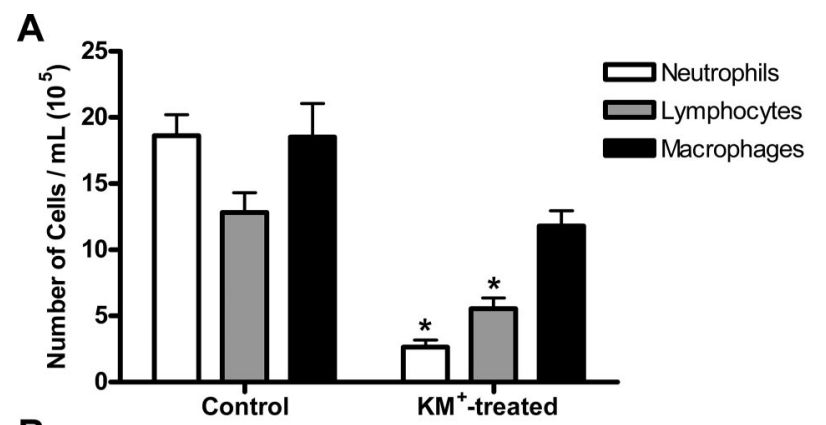

B

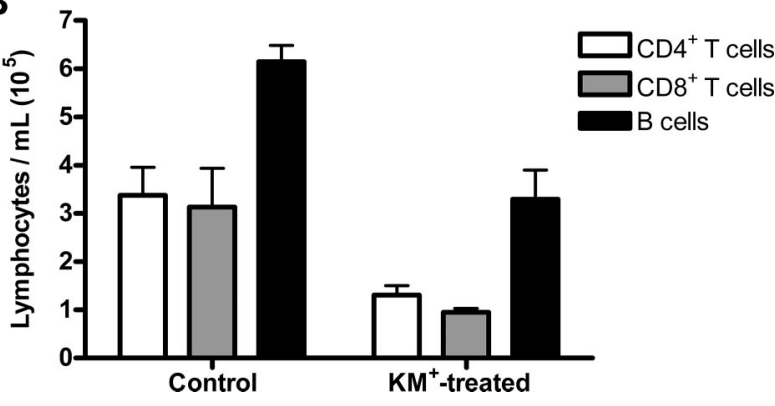

Figure 3. Leukocytes into the bronchoalveolar fluid of the P. brasiliensisinfected mice treated or not with $\mathrm{KM}^{+}$. A: Cells from BALF, obtained 30 days after infection, were categorized as neutrophils, lymphocytes, and macrophages according to morphological criteria. B: Lymphocytes from BALF were analyzed by flow cytometry after labeling with CD4, CD8, and CD19 cell markers. Total number of viable cells was determined by hemocytometer count and exclusion of trypan blue. The results represent the mean $\pm \mathrm{SD}$ of five mice per group. ${ }^{*} P<0.05$ versus control (PBS). 
lymphocyte populations by flow cytometry revealed that vehicle-treated mice had larger numbers of T (CD4 and $\mathrm{CD} 8$ ) and $\mathrm{B}$ cells compared to $\mathrm{KM}^{+}$-treated mice (Figure 3B), although no statistical difference was obtained. Although the absolute number of each lymphocyte population from treated and non-treated mice was different, the proportion of such populations was similar between the groups (Figure 3B). Thus, the lung histopathology and the BALF cell content are in agreement with the CFU data, indicating that $\mathrm{KM}^{+}$treatment triggers increased clearance of infectious burden from the lungs, liver, and spleen, thereby leading to a beneficial effect against $P$. brasiliensis infection.

\section{$\mathrm{KM}^{+}$Increases the Production of Proinflammatory Cytokines and NO in P. brasiliensis-Infected Mice}

Since the $\mathrm{KM}^{+}$treatment was effective in reducing fungal burden and preserving the pulmonary parenchyma of $P$. brasiliensis-infected mice, we asked whether these effects were associated with a favorable milieu of pulmonary cytokines. When we analyzed the production of proand anti-inflammatory cytokines in the supernatants of lung homogenates from the $P$. brasiliensis-infected $\mathrm{BALB} / \mathrm{c}$ mice treated with $\mathrm{fKKM}^{+}$or $\mathrm{rKM}^{+}$, we observed that on day 30 postinfection the concentrations of IFN- $\gamma$, IL-12p70, and TNF- $\alpha$ in the lung homogenates from mice treated with $\mathrm{KM}^{+}$were significantly higher than those from mice given no therapy $(P<0.05)$ (Figure $1, \mathrm{~B}-\mathrm{D})$. In the same period of infection, the amount of IL-4 detected in the lung homogenates from control mice was 60\% higher than that detected in the $\mathrm{KM}^{+}$-treated mice (Figure 1B), although similar levels of IL-10 were detected in the lung homogenates of the $\mathrm{KM}^{+}$-treated and nontreated mice (Figure 2E). Assays to evaluate the nitrite production in the supernatants of lung homogenates from $\mathrm{BALB} / \mathrm{c}$ mice showed that at 30 days postinfection the levels were higher in those injected with $\mathrm{jfKM}^{+}$or $\mathrm{rKM}^{+}$ than in the nontreated mice (Figure 1F).

\section{Protective Effect of $\mathrm{KM}^{+}$on $\mathrm{P}$. brasiliensis Infection Depends on IL-12 but Not on NO}

To determine whether the protection induced by $\mathrm{KM}^{+}$ against $P$. brasiliensis infection requires $\mathrm{IL}-12$ and $\mathrm{NO}$, whose production was shown to be increased in $\mathrm{KM}^{+}$treated mice, we performed experiments of fungal infection in IL-12- or NOS2-deficient mice, both from a C57BL/6 background. The administration of $\mathrm{KM}^{+}$was performed as described to BALB/c mice, ie, on day 10 after intravenous infection.

Histopathology of lung sections in the $\mathrm{KM}^{+}$-treated NOS2 ${ }^{-1-}$ and WT mice at 14 days postinfection showed a preserved organ architecture with few and small mononuclear infiltrates, where rare fungal cells were seen (Figure $4, B$ and $D$, respectively). In contrast, the pulmonary tissue of the $\mathrm{NOS}^{-1-}$ and WT mice given no therapy presented confluent granulomas (Figure 4, A and C, re-

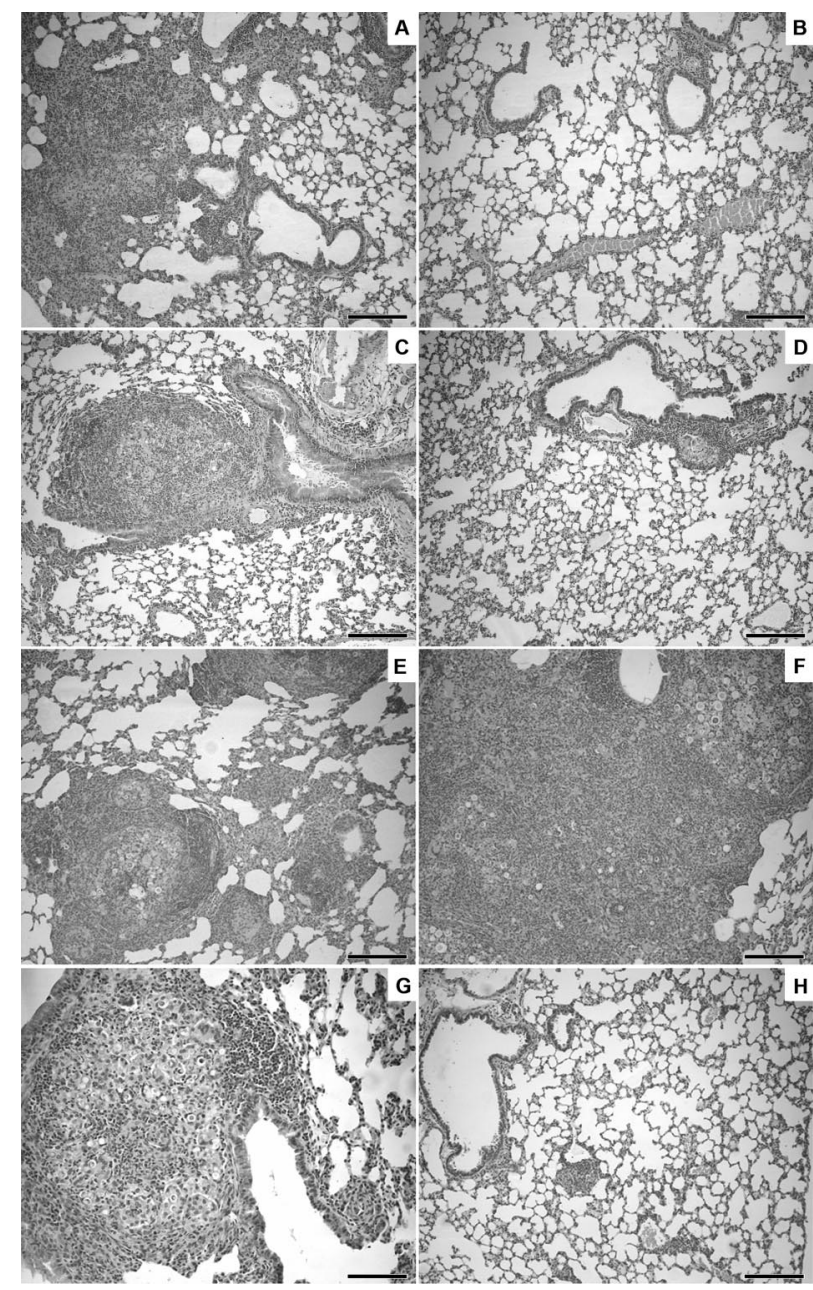

Figure 4. Therapeutic effect of $\mathrm{KM}^{+}$on $P$. brasiliensis infection depends on IL-12 but not on NO. A-D: Lung sections from NOS2 $2^{-/-}$mice and their WT counterpart obtained at 14 days postinfection were H\&E stained. The lung of $\mathrm{NOS}^{-1-}$ or WT mice treated with $\mathrm{jfKM}^{+}(\mathbf{B}$ and D) presented normal architecture and rare foci of mild inflammation, while the lung from mice given PBS presented confluent granulomas surrounding yeast cells ( $\mathbf{A}$ and C). E-H: Lung sections from IL- $12^{-/-}$mice and their WT counterpart obtained at 30 days postinfection were H\&E stained. The lung sections of IL-12 $2^{-/-}$mice treated (F) or not (E) with jfKM ${ }^{+}$presented severe granulomatous inflammation reaction similar to those observed in WT mice injected with PBS (G). Infected WT mice treated with $\mathrm{jKKM}^{+}$presented only very mild inflammatory reaction $(\mathbf{H})$. Scale bars $=200 \mu \mathrm{m}$.

spectively), reproducing destructive lesions observed in the nontreated BALB/c mice (Figure 1, A and C). Histopathology of the $\mathrm{NOS}^{-1-}$ mice on day 30 postinfection was not performed because the mice that were not treated with $\mathrm{KM}^{+}$had died by this time point.

On the other hand, the $\mathrm{IL}-12^{-/-}$mice treated or not with $\mathrm{KM}^{+}$presented a random fungal distribution and multiple confluent granulomas of varying sizes on day 14 (data not shown), which resulted in extensive lung destruction on day 30 postinfection (Figure 4, E and F). Concomitantly, many granulomatous infiltrates and a large number of viable yeast cells were seen in the liver and spleen of the IL-12 $2^{-1-}$ mice (data not shown). When the WT mice were injected with PBS, they developed focal and confluent granulomas circumscribing yeast cells (Figure 4, C and G). These same mice presented 

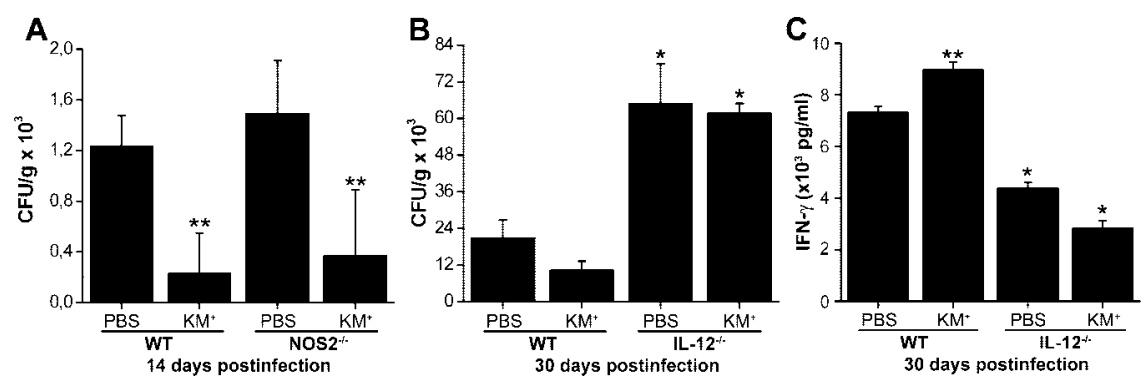

rare and small foci of inflammatory cells, without yeasts, (Figure 4, D and $\mathrm{H}$ ) when they were treated with $\mathrm{KM}^{+}$.

The pulmonary fungal burden was used to evaluate the involvement of $\mathrm{NO}$ and IL-12 on the therapeutic effect of $\mathrm{KM}^{+}$against $P$. brasiliensis infection. In agreement with the histopathology, $\mathrm{KM}^{+}$-treated NOS2${ }^{-/-}$mice were not more susceptible than $\mathrm{KM}^{+}$-treated WT mice to $P$. brasiliensis infection on day 14 postinfection, since the fungal load in the lungs of the $\mathrm{KM}^{+}$-treated mice was not significantly different (Figure 5A). Nevertheless, the number of yeasts recovered from the mice given no therapy were at least fourfold higher than those of the $\mathrm{KM}^{+}$-treated mice $(P<0.05)$, independent of their being $\mathrm{NOS}^{-1-}$ or WT (Figure 5A). Meanwhile, $\mathrm{IL}-12^{-1-}$ mice were compared with their counterparts in terms of their ability to control the $P$. brasiliensis infection (Figure 5). The mean number of $P$. brasiliensis recovered from $\mathrm{IL}-12^{-1-}$ mice treated or not with $\mathrm{KM}^{+}$did not differ significantly (Figure 5B). On the other hand, the number of yeasts from $\mathrm{KM}^{+}$-treated $\mathrm{IL} 12^{-1-}$ mice was at least threefold higher than that recovered from $\mathrm{KM}^{+}$-treated WT mice $(P<0.05)$ (Figure $5 \mathrm{~B})$. Among the WT mice, the number of CFU recovered from the $\mathrm{KM}^{+}$-treated group was 50\% lower compared to the control group (Figure 5B). The liver and spleen from the WT mice given PBS or from the $\mathrm{IL}-12^{-1-}$ mice treated or not with $\mathrm{KM}^{+}$still presented CFU burden at 30 days after infection (data not shown).

In addition, we examined IFN- $\gamma$ production in the IL$12^{-1-}$ mice. The IFN- $\gamma$ levels detected in the lung homogenates from $\mathrm{IL}_{-12^{-1-}}$ mice treated or not with $\mathrm{KM}^{+}$were at least $40 \%$ lower $(P<0.05)$ than the levels provided by WT mice (Figure 5C). In agreement with the IFN- $\gamma$ levels detected in the lung homogenates of BALB/c mice, the levels produced by the C57BL/6 mice were significantly higher $(P<0.05)$ in the $\mathrm{KM}^{+}$-treated mice than in the nontreated ones (Figure 5C).

\section{$\mathrm{KM}^{+}$-Stimulated Macrophages from TLR2 ${ }^{-/-}$ and MyD88 ${ }^{-1-}$ Deficient Mice Do Not Produce IL-12}

We had previously demonstrated that $\mathrm{KM}^{+}$induces IL-12 production by macrophage cell lines as well as peritoneal and spleen macrophages. ${ }^{21}$ To determine whether this property of $\mathrm{KM}^{+}$could be demonstrated in the MyD88 ${ }^{-1-}$ mice, we next determined the in vitro IL-12p70 production

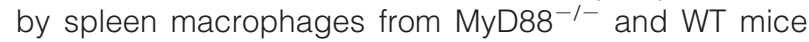

Figure 5. $\mathrm{KM}^{+}$does not protect $\mathrm{IL}-12^{-/-}$ mice from $P$. brasiliensis infection but protects NOS2 $2^{-1-}$ and WT mice evenly. NOS2 ${ }^{-/-}$(A) and IL-12 $2^{-1-}$ (B and $\mathbf{C}$ ) mice, as well as their WT counterpart, were intravenously infected with $10^{6} \mathrm{P}$. brasiliensis yeast cells and treated or not with $\mathrm{fKM}^{+} 10$ days postinfection. The number of viable yeasts (A and $\mathbf{B}$ ) and the IFN- $\boldsymbol{\gamma}$ production (C) were determined by CFU and capture ELISA, respectively, on day 14 after infection for the NOS $2^{-/-}$mice and on day 30 for the $\mathrm{IL}-12^{-/-}$mice. The results represent the mean $\pm \mathrm{SD}$ of three mice per group and are representative of at least two experiments. ${ }^{*} P<0.05$ versus control group (WT); ${ }^{* *} P<0.05$ versus WT control (PBS). stimulated with $5 \mu \mathrm{g}$ of $\mathrm{KM}^{+}$. We observed that the $\mathrm{KM}^{+}$stimulated macrophages from MyD88 ${ }^{-1-}$ mice but not from WT mice were unable to release IL-12 in culture supernatants (data not shown), suggesting that the IL-12 production induced by $\mathrm{KM}^{+}$can be dependent on the TLRs/MyD88 signaling pathway. To investigate the possible role of TLR2 or TLR4 in the IL-12 production induced by $\mathrm{KM}^{+}$, we compared the $\mathrm{IL}-12 \mathrm{p} 70$ concentrations released by $\mathrm{KM}^{+}$-stimulated macrophages from $\mathrm{TLR}^{-1-}$ versus TLR2 ${ }^{+/+}$mice or from TLR4 deficient versus WT mice. As shown in Figure 6, macrophages from TLR2 ${ }^{-/-}$ mice but not from TLR4-deficient mice and control mice did not produce $\mathrm{IL}-12$ in response to $\mathrm{KM}^{+}$or in response to zymosan. Moreover, IL-12 production by $\mathrm{KM}^{+}$-stimulated macrophages was inhibited by 50 mmol/L D-mannose, which is a $\mathrm{KM}^{+}$-specific monosaccharide. These results not only indicate that TLR2 plays a critical role in $\mathrm{IL}-12$ production mediated by $\mathrm{KM}^{+}$but also that cell stimulation occurs in a carbohydrate recognition-dependent manner.

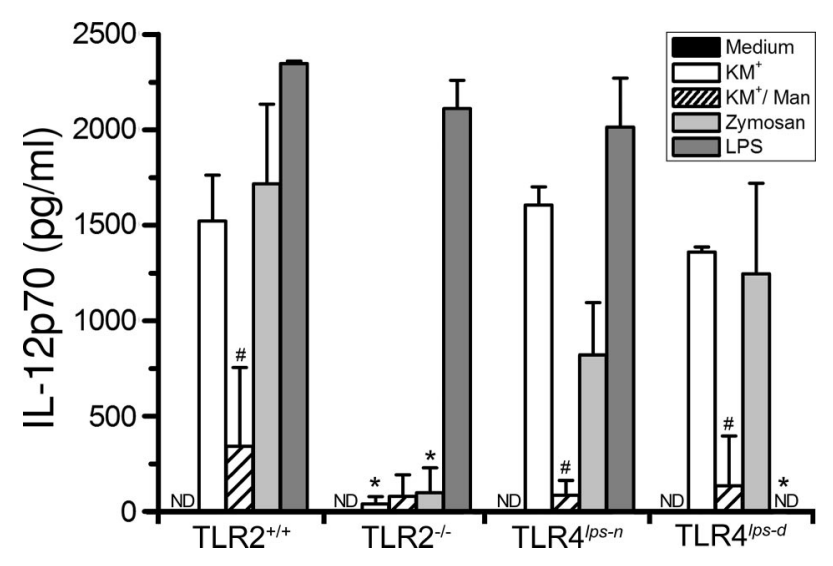

Figure 6. $\mathrm{KM}^{+}$induces IL-12 production by macrophages in a TLR2-dependent mechanism. Peritoneal macrophages from TLR2 ${ }^{+/+}(\mathrm{C} 57 \mathrm{BL} / 6)$, $\mathrm{TLR}^{-/-}, \mathrm{C} 3 \mathrm{H} / \mathrm{HePas}$ (TLR4 $4^{\text {lps } n}$, expressing a functional TLR4), and C3H HeJ (TLR $4^{l p s-d}$, expressing a nonfunctional TLR4) mice were cultured for 48 hours in the presence or absence of jfKM ${ }^{+}(5 \mu \mathrm{g} / \mathrm{ml})$, zymosan $(10 \mu \mathrm{g} / \mathrm{ml})$, or lipopolysaccharide $(10 \mu \mathrm{g} / \mathrm{ml})$. In some experiments, macrophages were cultured with $\mathrm{fKM}^{+}$in the presence of $50 \mathrm{mmol} / \mathrm{L} \mathrm{D}-\mathrm{mannose}\left(\mathrm{KM}^{+} / \mathrm{D}-\mathrm{Man}\right)$. The amount of IL-12p70 in the supernatant was determined by capture ELISA. Assays were performed in triplicate and the results represent the mean $\pm \mathrm{SD}$ of at least three independent experiments. ${ }^{*} P<0.05$ versus control group; $\# P<0.05$ versus positive control $\left(\mathrm{KM}^{+}\right)$. ND, not detected. 


\section{Discussion}

$\mathrm{KM}^{+}$lectin stimulates BALB/c macrophages to produce $\mathrm{IL}-12$, which promotes IFN- $\gamma$ production and protection against challenge with Leishmania through the induction of Th1-biased immunity. Since this prophylactic effect of $\mathrm{KM}^{+}$seems to be independent of the administration of specific antigen(s), ${ }^{21}$ new questions related to the therapeutic use of this lectin as well as its applicability to other intracellular pathogens have emerged. The current study was undertaken to investigate whether $\mathrm{KM}^{+}$could modify the course of $P$. brasiliensis infection when administered in therapeutic regimens. Protective effect was induced by both plant and recombinant forms of the lectin; ie, jfKM ${ }^{+}$ and $\mathrm{rKM}^{+}$, respectively. The Th1-biased immune response reduced the severity of the disease, as determined by CFU recovery and lung histopathology parameters. These results, determined 30 days after yeast inoculation, confirmed the ability to discriminate between susceptible and resistant mice to systemic fungal infection. ${ }^{28-31}$ The infected mice not treated with lectin presented with extensive fungal burden and pulmonary granulomatous lesions that characterize severe PCM, accompanied by exudation of inflammatory cells into the bronchoalveolar fluid. In contrast, the animals treated with jfKM ${ }^{+}$or $\mathrm{rKM}^{+}$presented sterile granulomatous lung inflammation and significantly decreased exudation of leukocytes into the BALF. These results demonstrate the efficacy of therapeutic administration of plant and recombinant $\mathrm{KM}^{+}$in inducing protection against $P$. brasiliensis murine infection.

Considering that cytokines play a crucial role in the course of human ${ }^{32-36}$ and experimental ${ }^{11,37-40} \mathrm{PCM}$, we evaluated the amount of pro- and anti-inflammatory cytokines in the lung homogenates from the $\mathrm{KM}^{+}$-treated mice and the control mice given no therapy at 30 days after infection. $\mathrm{KM}^{+}$-treated mice exhibited a noticeable increase in the pulmonary levels of IL-12p70, IFN- $\gamma$, and TNF- $\alpha$, consistent with the observed low fungal burden in the organs. Furthermore, a lower amount of the antiinflammatory cytokine IL-4 was detected in the lung homogenates from these mice compared with the amount provided by controls. Likewise, the levels of nitrite in the lungs from $\mathrm{KM}^{+}$-treated mice were higher than those found in nontreated controls.

Our results show that $\mathrm{KM}^{+}$administration is potentially useful, with the cytokine and the CFU data indicating that the generation of a new lung environment possibly leads to better control of fungal growth and impairs yeast dissemination. Most importantly, despite the high pulmonary levels of inflammatory cytokines, the therapeutic regimen of $\mathrm{KM}^{+}$does not lead to the tissue inflammatory injury commonly observed when exogenous IL-12 is administered. ${ }^{37}$ In addition, the administration of lectin did not elicit an anti-KM+ humoral response (data not shown). These data favor the idea of the pharmaceutical applicability of $\mathrm{KM}^{+}$.

Since there is evidence that the lectin $\mathrm{KM}^{+}$induces $\mathrm{IL}-12^{21}$ and that this cytokine together with $\mathrm{NO}$ plays an essential role in the protective response against intracellular pathogens, further experiments using genetically deficient mice were undertaken to better understand whether the induction of IL-12 and NO production could be directly correlated with the protection provided by $\mathrm{KM}^{+}$against $P$. brasiliensis infection. First and foremost, the fungal load recovered from wild-type controls and NOS2 ${ }^{-1-}$ mice given no therapy (PBS) did not differ significantly. Our data are in contrast with previous data, which state that NOS2-derived NO plays a fundamental role in the effector mechanism for controlling the fungal growth. ${ }^{41}$ Although NO has been reported to be crucial for the control of numerous intracellular pathogens, ${ }^{42}$ including $P$. brasiliensis, its overproduction has been associated with PCM susceptibility. ${ }^{41,43}$ Second, and consistently with the first remark, the NOS2 ${ }^{-1-}$ mice treated with $\mathrm{KM}^{+}$were not more susceptible to $P$. brasiliensis infection than the $\mathrm{KM}^{+}$-treated WT mice. Again, analysis of both these groups revealed a similar pattern of pulmonary lesions and the CFU burden recovered from their lungs did not differ significantly. The most striking differences were observed comparing the fungal load between mice treated with $\mathrm{KM}^{+}$or not. The $\mathrm{KM}^{+}$therapy led to significantly decreased number of $P$. brasiliensis yeast cells in the lungs from WT and NOS2 $2^{-1-}$ mice. Consequently, we can conclude that the mechanism by which $\mathrm{KM}^{+}$therapy induces protection in $P$. brasiliensis infection is not fundamentally due to the induction of NO production. It is possible that other microbicidal mechanisms dependent on IFN- $\gamma$ are involved in the efficacy of $\mathrm{KM}^{+}$ therapy, such as production of reactive oxygen intermediates, tryptophan degradation by the enzyme indoleamine 2,3-dioxygenase, deprivation of intracellular iron, and unidentified mechanism(s) mediated by 47 - to $48-\mathrm{kd}$ proteins encoded by an IFN- $\gamma$ responsive gene family. ${ }^{44}$ Besides, the two genetically established antimicrobial mechanisms of macrophages are production of reactive oxygen intermediates by phagocyte oxidase (phox) and reactive nitrogen intermediates by inducible nitric oxide synthase (NOS2). It has been demonstrated that there is an association between higher levels of $\mathrm{H}_{2} \mathrm{O}_{2}$ and higher fungicidal effect in PCM patients, which suggests that $\mathrm{O}_{2}$ metabolites are involved in the killing of $P$. brasiliensis by macrophages. ${ }^{45}$ Recently, it has been demonstrated that $\mathrm{H}_{2} \mathrm{O}_{2}$ is involved in the killing of highly virulent strains of $P$. brasiliensis by TNF- $\alpha$-activated human monocytes. ${ }^{46}$ In addition, a previous study reported that phox, the major source of reactive oxygen intermediate production, and NOS2 appears to compensate in large part for the isolated deficiency of the other. ${ }^{47}$

The investigation concerning the role of $\mathrm{IL}-12$ in the protection induced by $\mathrm{KM}^{+}$was outstandingly stimulated by reports of association between neutralization of endogenous IL-12 or the use of IL $12^{-1-}$ mice and increased fungal burden, severe pulmonary lesions, and susceptibility of mice not only to $P$. brasiliensis but also to Histoplasma capsulatum. ${ }^{48-50}$ In fact, PCM appears to be much more severe in the IL12 $12^{-1-}$ mice treated or not with $\mathrm{KM}^{+}$than in the WT animals, as reflected by the destructive granulomatous lesions and high fungal burden. These data undeniably indicate that the induction of endogenous IL-12 is critical in the mechanism by which $\mathrm{KM}^{+}$administration results in resistance against $P$. bra- 
siliensis infection. We also observed that when compared with WT mice, IL $12^{-1-}$ mice secrete noticeably lower levels of IFN- $\gamma$ in the lungs. The deficiency of IFN- $\gamma$ also leads to the development of incipient granulomas, which are unable to prevent fungal dissemination. ${ }^{29,40}$ The absence of $\mathrm{IL}-12$ production in $\mathrm{KM}^{+}$-stimulated macrophages from MyD88 ${ }^{-1-}$ mice demonstrates that the lectin acts by a mechanism that is dependent on the adaptor molecule MyD88 and suggests that the cytokine production is triggered by TLR signaling.

All members of the TLR family, with the exception of TLR3, trigger a pathway that depends on MyD88 to produce proinflammatory cytokines. ${ }^{51}$ Among them, TLR4 and TLR2 have been demonstrated to play a crucial role in fungal infections. ${ }^{52}$ Therefore, we evaluated whether one of these receptors could account for IL-12 production. In agreement with our previous studies, ${ }^{21}$ we verified herein that, following $\mathrm{KM}^{+}$-stimulation, IL-12 production is detected in macrophages from the $\mathrm{C} 3 \mathrm{H} / \mathrm{HeJ}$ mice, which harbor a spontaneous point mutation (Pro712His712) in the cytoplasmic signaling domain of TLR4. ${ }^{53}$ Conversely, the TLR2-deficient macrophages stimulated with $\mathrm{KM}^{+}$do not produce IL-12. In other words, we have shown that TLR2, but not TLR4, plays an essential role in triggering the signal transduction that leads to IL-12 production in response to $\mathrm{KM}^{+}$treatment.

Bearing in mind that, contrary to $\mathrm{TLR} 4^{-1-}$, macrophages from TLR2 ${ }^{-1-}$ and MyD88 ${ }^{-1-}$ do not produce $\mathrm{IL}-12$, and knowing that D-mannose inhibits the IL-12 production induced in vitro by $\mathrm{KM}^{+}$, we hypothesize that the cell stimulation occurs in a carbohydrate recognitiondependent manner, in which $\mathrm{KM}^{+}$interacts directly with the N-glycans of TLR2. Several lines of evidence indicate that carbohydrates attached to TLRs play important roles in agonist binding and in the formation of a functional receptor complex on the cell surface. ${ }^{54-58}$ Indeed, the study of Weber et $\mathrm{al}^{58}$ provided structural basis for our hypothesis, since it demonstrated that TLR2 undergoes glycosylation at Asn114, Asn199, Asn414, and Asn442, and these authors rationally proposed that glycans attached to Asn199, Asn414 and Asn442 are exposed to the concave surface of the solenoid structure of the TLR2 leucine-rich ectodomain. A recent report ${ }^{59}$ showed that at least two N-linked glycans in the TLR2 concave surface, most importantly the glycan linked to Asn442, are required for recognition of pathogen-associated molecular patterns. The $\mathrm{N}$-glycans associated with TLR2 are likely targets for $\mathrm{KM}^{+}$recognition, which could elicit the signaling cascade that leads to IL-12 production.

We cannot exclude the participation of other receptors than TLR2 in the signaling triggered by $\mathrm{KM}^{+}$to induce IL-12 production. It is known that highly purified TLR2 stimuli are poor inducers of IL-12 $2^{60,61}$ and often induce expression of low levels of p40 only. ${ }^{62}$ The production of the IL-12 heterodimer can be synergized by certain binary combinations of TLRs that result in the secretion of much more IL-12. ${ }^{63}$ In addition, dectin-1 has been identified as an important partner for TLR2 in mediating IL-12 production. ${ }^{16}$ Besides signaling through cell surface receptors, the additional interaction of agonists with intracellular Nod molecules leads to the synergistic activation of innate immune cells. ${ }^{64}$ Further investigation is necessary to identify cooperative molecule(s) that act in a synergistic way with TLR2, thereby allowing high IL-12 secretion in response to $\mathrm{KM}^{+}$stimulus.

The current antifungal therapies are limited because many targets are shared between pathogen and host, causing toxicity when used therapeutically. ${ }^{65}$ In addition, no standardized vaccines exist for preventing any of the human infections caused by fungi. So improvement of the host immune functions, like the one apparently promoted by $\mathrm{KM}^{+}$, can be a good strategy for the treatment of fungal infections in susceptible patients. The interference in the Th1/Th2 cell balance itself is certainly an adequate target of immunotherapy, and $\mathrm{KM}^{+}$favors Th1 response by interacting with TLR2 and inducing the consequent production of IL-12. Romani66 considered that the ultimate challenge in the therapeutic prospects of fungal infections would be to design vaccines that could induce optimal immune responses by targeting specific receptors on dendritic cells in vivo. We argue that the lectin $\mathrm{KM}^{+}$can contribute to facing such challenge.

In conclusion, we have shown that $\mathrm{KM}^{+}$can be protective against $P$. brasiliensis experimental infection, leading to a Th1-biased immune response with a direct beneficial effect on the severity of the lung lesions. Undeniably, the mechanism by which $\mathrm{KM}^{+}$leads to resistance against $P$. brasiliensis is due to the induction of endogenous IL-12 in a process dependent on the MyD88/TLR2 signaling pathway. Overall, these data open perspectives and provide additional support for the potential use of $\mathrm{KM}^{+}$as an immunomodulator molecule that is able to stimulate the Th1 response required to induce resistance to the fungal infection.

\section{Acknowledgments}

We thank Maria Helena Borges Malta, Sandra M.O. Thomaz, and Vani Maria Alves Correa for technical assistance. We thank Prof. Dr. João Santana da Silva and Dr. Emerson Soares Bernardes for helpful discussions.

\section{References}

1. Brummer E, Castaneda E, Restrepo A: Paracoccidioidomycosis: an update. Clin Microbiol Rev 1993, 6:89-117

2. McEwen JG, Bedoya V, Patino MM, Salazar ME, Restrepo A: Experimental murine paracoccidiodomycosis induced by the inhalation of conidia. J Med Vet Mycol 1987, 25:165-175

3. Almeida SR, Moraes JZ, Camargo ZP, Gesztesi JL, Mariano M, Lopes JD: Pattern of immune response to GP43 from Paracoccidioides brasiliensis in susceptible and resistant mice is influenced by antigen-presenting cells. Cell Immunol 1998, 190:68-76

4. Franco M, Montenegro MR, Mendes RP, Marques SA, Dillon NL, Mota NG: Paracoccidioidomycosis: a recently proposed classification of its clinical forms. Rev Soc Bras Med Trop 1987, 20:129-132

5. Arango M, Oropeza F, Anderson O, Contreras C, Bianco N, Yarzabal $\mathrm{L}$ : Circulating immune complexes and in vitro cell reactivity in paracoccidioidomycosis. Mycopathologia 1982, 79:153-158

6. Scott P, Kaufmann SH: The role of T-cell subsets and cytokines in the regulation of infection. Immunol Today 1991, 12:346-348

7. Scott P, Pearce E, Cheever AW, Coffman RL, Sher A: Role of cytokines and CD4+ T-cell subsets in the regulation of parasite immunity and disease. Immunol Rev 1989, 112:161-182

8. Hsieh CS, Macatonia SE, Tripp CS, Wolf SF, O'Garra A, Murphy KM: 
Development of TH1 CD4+ T cells through IL-12 produced by Listeria-induced macrophages. Science 1993, 260:547-549

9. Seder RA, Gazzinelli R, Sher A, Paul WE: Interleukin 12 acts directly on CD4+ T cells to enhance priming for interferon gamma production and diminishes interleukin 4 inhibition of such priming, Proc Natl Acad Sci USA 1993, 90:10188-10192

10. Macatonia SE, Hosken NA, Litton M, Vieira P, Hsieh CS, Culpepper JA, Wysocka M, Trinchieri G, Murphy KM, O'Garra A: Dendritic cells produce IL-12 and direct the development of Th1 cells from naive CD4+ T cells. J Immunol 1995, 154:5071-5079

11. Calich VL, Kashino SS: Cytokines produced by susceptible and resistant mice in the course of Paracoccidioides brasiliensis infection. Braz J Med Biol Res 1998, 31:615-623

12. Gay NJ, Gangloff M: Structure and function of toll receptors and their ligands. Annu Rev Biochem 2007, 76:141-165

13. Pluddemann A, Mukhopadhyay S, Gordon S: The interaction of macrophage receptors with bacterial ligands. Expert Rev Mol Med 2006, 8:1-25

14. Yamada C, Sano H, Shimizu T, Mitsuzawa H, Nishitani C, Himi T, Kuroki Y: Surfactant protein A directly interacts with TLR4 and MD-2 and regulates inflammatory cellular response. Importance of supratrimeric oligomerization, J Biol Chem 2006, 281:21771-21780

15. Frendeus B, Wachtler C, Hedlund M, Fischer H, Samuelsson P, Svensson M, Svanborg C: Escherichia coli $P$ fimbriae utilize the Toll-like receptor 4 pathway for cell activation. Mol Microbiol 2001, 40:37-51

16. Gantner BN, Simmons RM, Canavera SJ, Akira S, Underhill DM: Collaborative induction of inflammatory responses by dectin- 1 and Toll-like receptor 2. J Exp Med 2003, 197:1107-1117

17. Campbell D, Mann BJ, Chadee K: A subunit vaccine candidate region of the Entamoeba histolytica galactose-adherence lectin promotes interleukin-12 gene transcription and protein production in human macrophages. Eur J Immunol 2000, 30:423-430

18. Muraille E, Pajak B, Urbain J, Leo O: Carbohydrate-bearing cell surface receptors involved in innate immunity: interleukin-12 induction by mitogenic and nonmitogenic lectins. Cell Immunol 1999, 191:1-9

19. Hostanska K, Hajto T, Spagnoli GC, Fischer J, Lentzen H, Herrmann $R$ : A plant lectin derived from Viscum album induces cytokine gene expression and protein production in cultures of human peripheral blood mononuclear cells. Nat Immun 1995, 14:295-304

20. Pryjma J, Ernst M, Fetting R, Woloszyn M, Zembala M, Flad HD: The role of monocytes in the induction and regulation of IFN-gamma production by lectin-activated human T lymphocytes. Eur Cytokine Netw 1991, 2:273-279

21. Panunto-Castelo A, Souza MA, Roque-Barreira MC, Silva JS: KM(+), a lectin from Artocarpus integrifolia, induces IL-12 p40 production by macrophages and switches from type 2 to type 1 cell-mediated immunity against Leishmania major antigens, resulting in BALB/C mice resistance to infection. Glycobiology 2001, 11:1035-1042

22. Fava-Netto C, Vegas VS, Sciannaméa IM, Guarnieri DB: Antígeno polissacarídeo do Paracoccidioides brasiliensis. Estudo do tempo de cultivo do Paracoccidioides brasiliensis, necessário ao preparo do antígeno, Rev Inst Med Trop São Paulo 1969, 11:177-181

23. Calich VL, Purchio A, Paula CR: A new fluorescent viability test for fungi cells. Mycopathologia 1979, 66:175-177

24. Santos-de-Oliveira R, Dias-Baruffi M, Thomaz SM, Beltramini LM, Roque-Barreira MC: A neutrophil migration-inducing lectin from Artocarpus integrifolia. J Immunol 1994, 153:1798-1807

25. da Silva LL, Molfetta-Machado JB, Panunto-Castelo A, Denecke J, Goldman GH, Roque-Barreira MC, Goldman MH: cDNA cloning and functional expression of $\mathrm{KM}+$, the mannose-binding lectin from $\mathrm{Ar}$ tocarpus integrifolia seeds. Biochim Biophys Acta 2005, 1726: 251-260

26. Singer-Vermes LM, Ciavaglia MC, Kashino SS, Burger E, Calich VL: The source of the growth-promoting factor(s) affects the plating efficiency of Paracoccidioides brasiliensis. J Med Vet Mycol 1992, 30:261-264

27. Yoshii C, Nagata N, Tao Y, Suematsu R, Nikaido Y, Kido M: Relationship between inflammatory cells in bronchoalveolar lavage fluid and pathologic changes in the lung interstitium. Respiration 1998, 65:386-92

28. Borges-Walmsley MI, Chen D, Shu X, Walmsley AR: The pathobiology of Paracoccidioides brasiliensis. Trends Microbiol 2002, 10:80-87
29. Cano LE, Kashino SS, Arruda C, Andre D, Xidieh CF, Singer-Vermes LM, Vaz CA, Burger E, Calich VL: Protective role of gamma interferon in experimental pulmonary paracoccidioidomycosis. Infect Immun 1998, 66:800-806

30. Diniz SN, Cisalpino PS, Freire AT, Silva-Teixeira DN, Contigli C, Rodrigues Junior V, Goes AM: In vitro granuloma formation. NO production and cytokines profile from human mononuclear cells induced by fractionated antigens of Paracoccidioides brasiliensis, Hum Immunol 2001, 62:799-808

31. Singer-Vermes LM, Caldeira CB, Burger E, Calich LG: Experimental murine paracoccidioidomycosis: relationship among the dissemination of the infection, humoral and cellular immune responses. Clin Exp Immunol 1993, 94:75-79

32. Benard G, Romano CC, Cacere CR, Juvenale M, Mendes-Giannini MJ, Duarte AJ: Imbalance of IL-2. IFN-gamma and IL-10 secretion in the immunosuppression associated with human paracoccidioidomycosis, Cytokine 2001, 13:248-252

33. Karhawi AS, Colombo AL, Salomao R: Production of IFN-gamma is impaired in patients with paracoccidioidomycosis during active disease and is restored after clinical remission. Med Mycol 2000, 38: 225-229

34. Peraçoli MT, Kurokawa CS, Calvi SA, Mendes RP, Pereira PC, Marques SA, Soares AM: Production of pro- and anti-inflammatory cytokines by monocytes from patients with paracoccidioidomycosis. Microbes Infect 2003, 5:413-418

35. Romano CC, Mendes-Giannini MJ, Duarte AJ, Benard G: IL-12 and neutralization of endogenous IL-10 revert the in vitro antigen-specific cellular immunosuppression of paracoccidioidomycosis patients. Cytokine 2002, 18:149-157

36. Romano CC, Mendes-Giannini MJ, Duarte AJ, Benard G: The role of interleukin-10 in the differential expression of interleukin-12p70 and its beta2 receptor on patients with active or treated paracoccidioidomycosis and healthy infected subjects. Clin Immunol 2005, 114: 86-94

37. Arruda C, Franco MF, Kashino SS, Nascimento FR, Fazioli Rdos A, Vaz CA, Russo M, Calich VL: Interleukin-12 protects mice against disseminated infection caused by Paracoccidioides brasiliensis but enhances pulmonary inflammation. Clin Immunol 2002, 103:185-195

38. Arruda C, Valente-Ferreira RC, Pina A, Kashino SS, Fazioli RA, Vaz CA, Franco MF, Keller AC, Calich VL: Dual role of interleukin-4 (IL-4) in pulmonary paracoccidioidomycosis: endogenous IL-4 can induce protection or exacerbation of disease depending on the host genetic pattern. Infect Immun 2004, 72:3932-3940

39. Parise-Fortes MR, da Silva MF, Sugizaki MF, Defaveri J, Montenegro MR, Soares AM, Peracoli MT: Experimental paracoccidioidomycosis of the Syrian hamster: fungicidal activity and production of inflammatory cytokines by macrophages. Med Mycol 2000, 38:51-60

40. Souto JT, Figueiredo F, Furlanetto A, Pfeffer K, Rossi MA, Silva JS: Interferon-gamma and tumor necrosis factor-alpha determine resistance to Paracoccidioides brasiliensis infection in mice. Am J Pathol 2000, 156:1811-1820

41. Nascimento FR, Calich VL, Rodriguez D, Russo M: Dual role for nitric oxide in paracoccidioidomycosis: essential for resistance, but overproduction associated with susceptibility. J Immunol 2002, 168: 4593-4600

42. Nathan C: Inducible nitric oxide synthase: what difference does it make? J Clin Invest 1997, 100:2417-2423

43. Bocca AL, Hayashi EE, Pinheiro AG, Furlanetto AB, Campanelli AP, Cunha FQ, Figueiredo F: Treatment of Paracoccidioides brasiliensisinfected mice with a nitric oxide inhibitor prevents the failure of cell-mediated immune response. J Immunol 1998, 161:3056-3063

44. Suzuki Y: Immunopathogenesis of cerebral toxoplasmosis. J Infect Dis 2002, 186 Suppl 2:S234-240

45. Calvi SA, Peracoli MT, Mendes RP, Marcondes-Machado J, Fecchio D, Marques SA, Soares AM: Effect of cytokines on the in vitro fungicidal activity of monocytes from paracoccidioidomycosis patients. Microbes Infect 2003, 5:107-113

46. Carmo JP, Dias-Melicio LA, Calvi SA, Peracoli MT, Soares AM: TNFalpha activates human monocytes for Paracoccidioides brasiliensis killing by an H2O2-dependent mechanism. Med Mycol 2006, 44: 363-368

47. Shiloh MU, MacMicking JD, Nicholson S, Brause JE, Potter S, Marino M, Fang F, Dinauer M, Nathan C: Phenotype of mice and macro- 
phages deficient in both phagocyte oxidase and inducible nitric oxide synthase. Immunity 1999, 10:29-38

48. Allendoerfer R, Biovin GP, Deepe GS Jr: Modulation of immune responses in murine pulmonary histoplasmosis, J Infect Dis 1997, 175:905-914

49. Cain JA, Deepe GS Jr: Interleukin-12 neutralization alters lung inflammation and leukocyte expression of CD80, CD86, and major histocompatibility complex class II in mice infected with Histoplasma capsulatum, Infect Immun 2000, 68:2069-2076

50. Deepe GS Jr, Romani L, Calich VL, Huffnagle G, Arruda C, MolinariMadlum EE, Perfect JR: Knockout mice as experimental models of virulence. Med Mycol 2000, 38(Suppl 1):87-98

51. West AP, Koblansky AA, Ghosh S: Recognition and signaling by toll-like receptors. Annu Rev Cell Dev Biol 2006, 22:409-437

52. Netea MG, Van der Meer JW, Kullberg BJ: Role of the dual interaction of fungal pathogens with pattern recognition receptors in the activation and modulation of host defence. Clin Microbiol Infect 2006, 12:404-409

53. Poltorak A, He X, Smirnova I, Liu MY, Van Huffel C, Du X, Birdwell D, Alejos E, Silva M, Galanos C, Freudenberg M, Ricciardi-Castagnoli P, Layton B, Beutler B: Defective LPS signaling in $\mathrm{C} 3 \mathrm{H} / \mathrm{HeJ}$ and C57BL/ 10ScCr mice: mutations in TIr4 gene. Science 1998, 282:2085-2088

54. Choe J, Kelker MS, Wilson IA: Crystal structure of human toll-like receptor 3 (TLR3) ectodomain. Science 2005, 309:581-585

55. da Silva Correia J, Ulevitch RJ: MD-2 and TLR4 N-linked glycosylations are important for a functional lipopolysaccharide receptor. J Biol Chem 2002, 277:1845-1854

56. Ohnishi T, Muroi M, Tanamoto K: N-linked glycosylations at Asn(26) and Asn(114) of human MD-2 are required for toll-like receptor 4-mediated activation of NF-kappaB by lipopolysaccharide. J Immunol 2001, 167:3354-3359
57. Ohnishi T, Muroi M, Tanamoto K: MD-2 is necessary for the toll-like receptor 4 protein to undergo glycosylation essential for its translocation to the cell surface. Clin Diagn Lab Immunol 2003, 10:405-410

58. Weber AN, Morse MA, Gay NJ: Four N-linked glycosylation sites in human toll-like receptor 2 cooperate to direct efficient biosynthesis and secretion. J Biol Chem 2004, 279:34589-34594

59. Kataoka H, Yasuda M, Iyori M, Kiura K, Narita M, Nakata T, Shibata K: Roles of $\mathrm{N}$-linked glycans in the recognition of microbial lipopeptides and lipoproteins by TLR2. Cell Microbiol 2006, 8:1199-1209

60. Agrawal S, Agrawal A, Doughty B, Gerwitz A, Blenis J, Van Dyke T, Pulendran B: Different Toll-like receptor agonists instruct dendritic cells to induce distinct Th responses via differential modulation of extracellular signal-regulated kinase-mitogen-activated protein kinase and c-Fos. J Immunol 2003, 171:4984-4989

61. Kadowaki N, Ho S, Antonenko S, Malefyt RW, Kastelein RA, Bazan F, Liu YJ: Subsets of human dendritic cell precursors express different toll-like receptors and respond to different microbial antigens. J Exp Med 2001, 194:863-869

62. Trinchieri G, Sher A: Cooperation of Toll-like receptor signals in innate immune defence. Nat Rev Immunol 2007, 7:179-190

63. Napolitani G, Rinaldi A, Bertoni F, Sallusto F, Lanzavecchia A: Selected Toll-like receptor agonist combinations synergistically trigger a T helper type 1-polarizing program in dendritic cells. Nat Immunol 2005, 6:769-776

64. Delbridge LM, O'Riordan MX: Innate recognition of intracellular bacteria. Curr Opin Immunol 2007, 19:10-16

65. Odds FC, Brown AJ, Gow NA: Antifungal agents: mechanisms of action. Trends Microbiol 2003, 11:272-279

66. Romani L: Immunity to fungal infections. Nat Rev Immunol 2004, $4: 1-23$ 